\title{
Spironolactone and Enalapril Differentially Up-Regulate the Expression of VEGF and Heme Oxygenase-1 in the Neonatal Rat Kidney
}

\author{
HYUNG EUN YIM, JI HAE KIM, KEE HWAN YOO, IN SUN BAE, YOUNG SOOK HONG, AND JOO WON LEE
}

Department of Pediatrics, Korea University Medical Center, College of Medicine, Korea University, Seoul 152-703, Korea

\begin{abstract}
Both the renin-angiotensin-aldosterone system (RAAS) and hypoxia are vital physiological factors involved in the control of nephrogenesis and vascularization. We investigated the relationship between RAAS and hypoxia in the developing kidney. The expression of VEGF and heme oxygenase (HO)-1 related with the oxygen was analyzed in the enalapril- or spironolactone-treated neonatal rat kidneys. Enalapril $(30 \mathrm{mg} / \mathrm{kg} / \mathrm{d})$ or spironolactone $(200$ $\mathrm{mg} / \mathrm{kg} / \mathrm{d}$ ) was administered to newborn rat pups for $7 \mathrm{~d}$. The newborn rats were injected i.p. with pimonidazole $(200 \mathrm{mg} / \mathrm{kg})$, a marker of severe tissue hypoxia, $1 \mathrm{~h}$ before killing. VEGF and HO-1 protein expression was significantly increased by immunoblots and immunohistochemistry in both the enalapril- and spironolactone-treated kidneys, compared with the controls $(p<0.05)$. HO-1 mRNA expression was increased in the spironolactone-treated group $(p<$ 0.05 ). The immunoactivity of pimonidazole was not different from that of the controls in the enalapril-treated group, whereas it was increased in the spironolactone-treated group. The results of this study indicate that aldosterone blockade or angiotensin II inhibition in the developing rat kidney up-regulated renal VEGF and HO-1 expression regardless of the hypoxic conditions and may differentially modulate VEGF and HO-1 production. (Pediatr Res 69: 378-383, 2011)
\end{abstract}

$\mathrm{I}_{\mathrm{a}}^{\mathrm{n}}$ the developing kidney, all components of the reninangiotensin-aldosterone system (RAAS) are expressed in a spatial and temporal pattern that is linked to the specific stages of nephrogenesis and vascularization (1). Pharmacological inhibition of the RAAS during the neonatal period in rodents, during the time when nephrogenesis is ongoing and arteriolar branching is at its peak, has shown an arrest in the branching of the kidney arterioles and abnormal thickening of the wall of the intrarenal arterioles, in addition to renal papillary atrophy and tubulointerstitial damage (2).

Nephrogenesis is accompanied by the coordinated branching of the renal tubular and vascular system; hypoxia has been proposed as a major regulatory factor during this process. A mismatch of oxygen demand and vascularization during kidney microvascular development contributes to regional hypoxia, which is thought to play a crucial role in tissue maturation (3). In turn, the hypoxic response induces

Received July 29, 2010; accepted November 15, 2010.

Correspondence: Kee Hwan Yoo, M.D., Ph.D., Department of Pediatrics, Guro Hospital, Korea University Medical Center, \#80, Guro-Dong, Guro-Gu, Seoul 152-703, Korea; e-mail: guroped@korea.ac.kr

H.E.Y. and J.H.K. contributed equally to this work.

Supported by a research grant from the Korean Society of Nephrology. the increased expression of genes that promote new blood vessel formation (vasculogenesis), induces the expansion of the existing vasculature (angiogenesis), and allows for anaerobic glycolysis (4).

The VEGF is a key modulator of vasculogenesis and angiogenesis in physiological and pathological conditions; it is a potent mitogen and chemoattractant for endothelial cells. VEGF plays a key role in the development and maintenance of the early vasculature of the kidney and later during the neonatal period with the continued development of the kidney (5). Mice with targeted inactivation of the $V E G F$ gene have shown early embryonic lethality and failure of vasculogenesis. In addition, the overexpression of VEGF in transgenic mice has resulted in malformed and dysfunctional blood vessel development (6,7). Enhancement of VEGF expression is mediated by hypoxia, cytokines, growth factors, NO, and the reactive oxygen species (5). Several studies have shown that angiotensin (Ang) II or aldosterone (Aldo) up-regulates renal VEGF expression through diverse mechanisms (8-10).

Among the hypoxia-responsive target genes, heme oxygenase (HO)-1 has been implicated in angiogenesis. It seems to be involved in both upstream of VEGF synthesis and downstream of the VEGF-mediated activation of endothelial cells (11). HO-1 catalyzes the rate-limiting step of heme oxidation to carbon monoxide, iron, and biliverdin. Biliverdin is subsequently converted by biliverdin reductase to bilirubin, a molecule with antioxidant properties (12). In the unstressed kidneys, HO-1 is weakly expressed in the renal tubules. However, under stressful conditions, HO-1 is strongly induced in the renal tubules and arterioles (13). Induction of HO-1 has been shown to decrease Aldo synthesis in a rat model of renovascular hypertension (14). Targeting the thick ascending limb of the loop of Henle for the human $\mathrm{HO}-1$ gene has been shown to decrease Ang II-mediated DNA damage (15).

We recently demonstrated that Aldo blockade, in the developing rat kidney, induces hypoxic response and upregulates the expression of key mediators of hypoxia including hypoxia-inducible factor (HIF)- $1 \alpha$ and Ets-1, whereas Ang II inhibition does not affect hypoxia-related alterations in

\footnotetext{
Abbreviations: ACE, angiotensin-converting enzyme; Aldo, aldosterone; Ang, angiotensin; GAPDH, glyceraldehyde-3-phosphate dehydrogenase; HIF, hypoxia-inducible factor; HO, heme oxygenase; RAAS, renin-angiotensin-aldosterone system
} 
the developing kidney (16). However, nonhypoxic HIF target gene expression occurs in certain cells under relatively normal oxygen pressures (17); little is known about the mechanisms involved in these activities. The objective of this study was to examine whether $V E G F$ and $H O-1$ genes are involved in hypoxia- and/or RAAS-regulated renal growth and maturation of the developing kidneys. The expression patterns of VEGF and HO-1 in newborn rat kidneys and enalapril- or spironolactone-treated kidneys were studied. In addition, the expression of pimonidazole, a recognized marker of severe tissue hypoxia, was also evaluated (18).

\section{MATERIALS AND METHODS}

Animal preparation. Neonatal rat pups from six pregnant Sprague Dawley rats were breastfed by their own mother throughout the study and divided into two groups. Group 1 was given $30 \mathrm{mg} / \mathrm{kg}$ of enalapril (the enalapril-treated group, $n=20$ ) dissolved with water or the same amount of vehicle (the control group $1, n=18$ ) via an orogastric tube. Group 2 was treated with $200 \mathrm{mg} / \mathrm{kg}$ of spironolactone (Sigma Chemical Co., St. Louis, MO) in olive oil (the spironolactone group, $n=22$ ) or olive oil (the control group 2, $n=19$ ). The rats were killed, and their kidneys were harvested at $8 \mathrm{~d}$ postpartum (N8). One whole kidney (right kidney) from each rat was used for light microscopy and immunohistochemistry and the other whole kidney (left kidney) for Western blot analysis. The experimental protocol was approved by the Animal Care Committee of the Korea University Guro Hospital.

$\boldsymbol{R T}$-PCR. The extraction of RNA, DNA, and protein from kidney tissues was performed as described previously (16).

cDNA synthesis by RT-PCR. Oligo dT-primed first-strand DNA was synthesized from the 1- $\mu \mathrm{L}$ RNA template using a cDNA synthesis kit (Boehringer Mannheim, Indianapolis, IN). Synthetic cDNA was used to amplify VEGF, HO-1, and glyceraldehyde-3-phosphate dehydrogenase $(G A P D H)$, a house-keeping gene. Using primers for GAPDH designed from DNA templates of rats (5'-AATGCATCCTGCACCACCAA-3' and 5'GTAGCCATATTCATGTCATA-3'), 515 bp of the PCR product were obtained (19). Products of $370 \mathrm{bp}$ and $450 \mathrm{bp}$ for VEGF and $181 \mathrm{bp}$ for HO-1 were obtained from the primers of VEGF $\left(5^{\prime}\right.$-TGCACCCACGACAGAAGGG-3' and 5'-TCACCGCCTTGGCTTGTCACAT-3') and HO-1 (5'ACTGCTGACAGAGGAACACAAA- $3^{\prime}$ and 5' -CAACAGGAAACTGAGTGTGAGG-3') (20,21). The PCR was performed with a different mode of time and temperature for each reaction product using the Perkin Elmer Cetus DNA Thermal Cycler (Model 2400, Foster City, CA). For GAPDH, the PCR was performed at 30 cycles of heating for $40 \mathrm{~s}$ at $94^{\circ} \mathrm{C}$ after denaturation for $5 \mathrm{~min}$ at $94^{\circ} \mathrm{C}$, followed by annealing for $40 \mathrm{~s}$ at $60^{\circ} \mathrm{C}$, and finally a primer extension for $1 \mathrm{~min}$ at $70^{\circ} \mathrm{C}$. For VEGF, the PCR was performed for 30 cycles of heating for $35 \mathrm{~s}$ at $94^{\circ} \mathrm{C}$ after denaturation for $5 \mathrm{~min}$ at $94^{\circ} \mathrm{C}$, followed by annealing for $35 \mathrm{~s}$ at $58^{\circ} \mathrm{C}$ and finally a primer extension for $50 \mathrm{~s}$ at $72[\mathrm{eg}] \mathrm{C}$. For HO-1, the PCR was performed for 30 cycles of heating for $45 \mathrm{~s}$ at $94^{\circ} \mathrm{C}$ after denaturation for $5 \mathrm{~min}$ at $94^{\circ} \mathrm{C}$, followed by annealing for $45 \mathrm{~s}$ at $57.5^{\circ} \mathrm{C}$ and a primer extension for $50 \mathrm{~s}$ at $72^{\circ} \mathrm{C}$. These amplified PCR products were visualized as fluorescent bands under UV light after electrophoresis on a $2 \%$ agarose gel at regular intervals and stained with ethidium bromide. Polaroid photographs were scanned using an Epson GT-9500 (Seiko Corp, Nagano, Japan) and quantified by densitometry (Image PC alpha 9; National Institutes of Health, Bethesda, MD). The values were standardized to GAPDH.

Western blotting. The extracted proteins were solubilized in $5 \times$ SDS loading buffer for $5 \mathrm{~min}$ at $95^{\circ} \mathrm{C}$ and separated by electrophoresis on $10 \%$ SDS-polyacrylamide gels under reducing conditions. Equal amounts of 5-15 $\mu \mathrm{g}$ of proteins were loaded per lane. Subsequently, the proteins were transferred to nitrocellulose membranes (Amersham Life Science, Buckinghamshire, England). The nitrocellulose membranes were blocked in 5\% skim milk with Tris Buffered Saline w/Tween 20 [TBS-T; $0.05 \%$ Tween 20 in $50 \mathrm{mM}$ of Tris, $150 \mathrm{mM}$ of $\mathrm{NaCl}$, and $0.05 \% \mathrm{NaN}_{3}(\mathrm{pH} \mathrm{7.4)}$ ] at room temperature for $1 \mathrm{~h}$. The membranes were washed two times in TBS-T and incubated for $18 \mathrm{~h}$ at $4^{\circ} \mathrm{C}$ with rabbit polyclonal antiserum (VEGF; dilution 1:200; Santa Cruz Biotechnology, Santa Cruz, CA) and HO-1 (dilution 1:500; Santa Cruz Biotechnology). Thereafter, the membranes were washed two times with TBS-T and incubated for $40 \mathrm{~min}$ with an anti-rabbit IgG (Amersham Life Science) and an anti-mouse $\operatorname{IgG}$ (Amersham Life Science) at room temperature. After washing with TBS-T four times, the secondary antibody bound to the nitrocellulose was detected by incubation for $1 \mathrm{~min}$ with a detection reagent (Amersham Life Science) and then exposed to medical x-ray film
(Agfa, Mortsel, Belgium) for $1 \mathrm{~min}$. The film was developed with the FPM-3500 Fuji x-ray Film Processor (Fuji, Otawara, Japan). Then, for stripping and reprobing, the same membranes were submerged in stripping buffer ( $2 \%$ SDS in $62.5 \mathrm{mM}$ of Tris-HCL and $0.1 \mathrm{M}$ of beta-mercaptoethanol) and incubated at $50^{\circ} \mathrm{C}$ for $10 \mathrm{~min}$ with occasional shaking. To control for equal loading, $\alpha$-tubulin (1:1000 dilution; Cell Signaling Technology, MA) and anti-mouse $\operatorname{IgG}$ conjugated horseradish peroxidase (1:1000 dilution; Amersham Life Science) were used as primary and secondary antibodies with the same method as described earlier. The developed x-rays were scanned using the Epson GT-9500 (Seiko Corp), and the results were quantified by densitometry (Image PC alpha 9).

Immunohistochemistry. For assessing expression, five kidneys in each group were selected for representative immunohistochemical staining of VEGF and HO-1, using an avidin-biotin immunoperoxidase method (Vectastain ABC kit, Burlingame, CA). Immunohistochemistry was performed on paraffin sections as described previously (16). Primary antibodies against VEGF (dilution 1:50; Santa Cruz Biotechnology) and HO-1 (dilution 1:100; Santa Cruz Biotechnology) were used.

Detection of hypoxic signals using pimonidazole adducts was investigated as in previous studies (16). A dose of $200 \mathrm{mg} / \mathrm{kg}$ of pimonidazole (Hypoxyprobe; Natural Pharmacia International, Inc., Belmont, MA) was injected i.p. into N8 rats $1 \mathrm{~h}$ before killing. Formalin-fixed sections were processed by an avidin-biotin immunoperoxidase method (Vectastain $\mathrm{ABC}$ kit) followed by exposure, for $40 \mathrm{~min}$, with 1:200 pimonidazoleadduct antibodies. The sections were then incubated for $10 \mathrm{~min}$ in rabbit anti-mouse $\mathrm{IgG}$ and streptavidin peroxidase. The immunoreaction products were developed in diaminobenzidine at standard development times. No counterstaining was performed.

Statistical analysis. Data are presented as the mean \pm SEM. Differences between the groups were analyzed with the $t$ test. Statistical significance was defined as a $p<0.05$. Sigmastat version 2.0 for Windows was used for the analysis.

\section{RESULTS}

VEGF expression. The immunoblots showed that the VEGF/tubulin protein expression was increased in the both enalapril- and spironolactone-treated groups compared with the control group ( $p<0.05$; Figs. $1 A$ and $2 A$ ). There was no difference in VEGF/GAPDH mRNA expression, as measured by the semiquantitative RT-PCR, between the two groups [enalapril versus control (Fig. 1B) and spironolactone versus
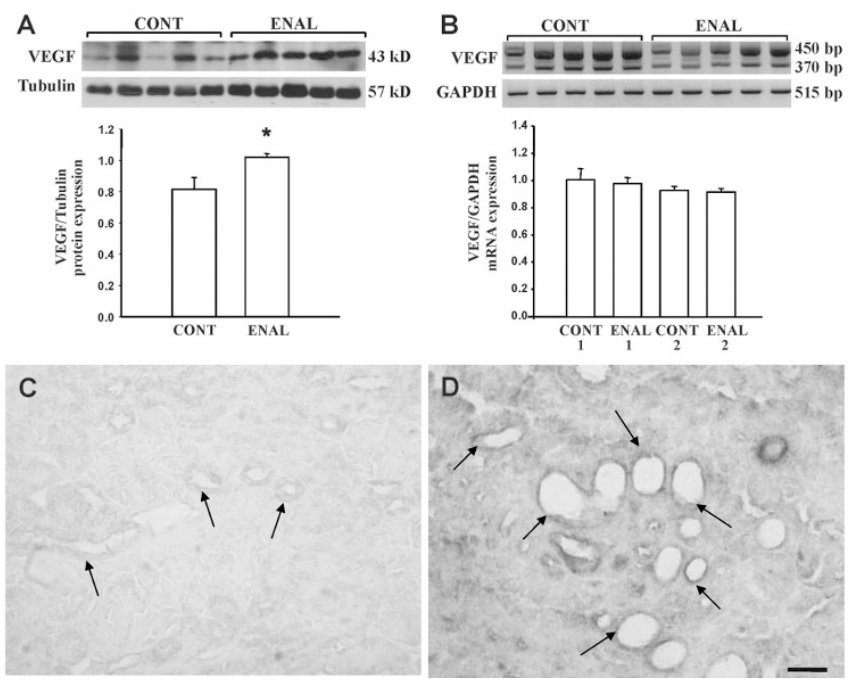

Figure 1. VEGF expression in the enalapril-treated group. (A) VEGF/ tubulin protein expression increased in the enalapril-treated group (ENAL) compared with the control group (CONT); ${ }^{*} p<0.05$. (B) RT-PCR showed no difference between the two groups. $(C)$ VEGF expression was observed in some tubular epithelial cells in the newborn control kidney (arrows). (D) In the enalapril-treated kidneys, VEGF was more significantly detected mainly in the dilated cortical tubules (arrows). $C$ and $D$ : bar, $25 \mu \mathrm{m}$, original magnification $\times 400$ ). 

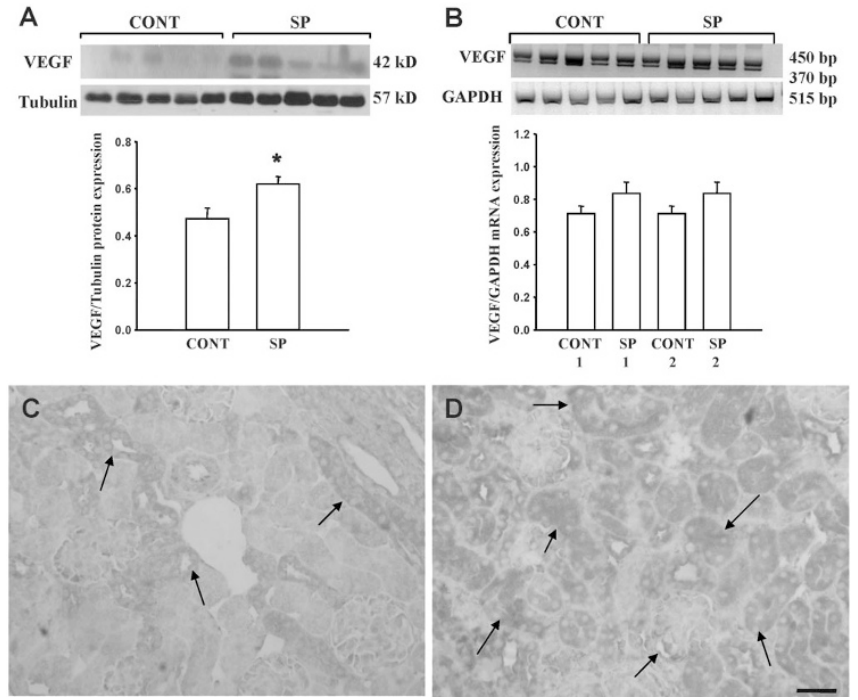

Figure 2. VEGF expression in the spironolactone-treated group. (A) VEGF/ tubulin protein expression increased in the spironolactone-treated group (SP) compared with the control group (CONT); $* p<0.05$. (B) RT-PCR showed no difference between the two groups. $(C)$ In the controls, VEGF was detected in some tubular epithelial cells (arrows). (D) In the spironolactone-treated kidneys, VEGF was more strongly expressed and distributed throughout almost all cortical tubular cells and glomeruli (arrows; $C, D$ bar $25 \mu \mathrm{m}$, original magnification $\times 400$ ).

control (Fig. 2B)]. The immunohistochemical staining showed that VEGF expression was detectable within some of the tubular epithelial cells and glomeruli in the cortex of the control group (Figs. $1 C$ and $2 C$ ). However, in the enalapriltreated group, it was more strongly expressed and distributed especially in the dilated cortical tubules (Fig. $1 D$ ). In the spironolactone-treated group, VEGF was vividly detected in almost all cortical developing and maturing tubular cells, compared with the controls (Fig. 2D).

HO-1 expression. HO-1/tubulin protein expression was increased in both the enalapril- and spironolactone-treated groups, compared with the control group ( $p<0.05$; Figs. $3 A$ and $4 A$ ). There was no difference in HO-1/GAPDH mRNA expression between the enalapril-treated group and the control group (Fig. 3B); however, HO-1/GAPDH mRNA expression was increased in the spironolactone-treated group, compared with the control group (Fig. 4B). Immunohistochemically, HO-1 expression was easily detected within the cortical tubular epithelial cells in the control group (Figs. $3 C$ and $4 C$ ). By comparison, it was more strongly detected in many dilated cortical tubules and glomeruli in the enalapril-treated group (Fig. 3D) and in almost all the cortical tubular segments in the spironolactone-treated group (Fig. 4D).

Detection of tissue hypoxia by pimonidazole adducts. Pimonidazole staining was observed in the developing and maturing tubular cells of control kidneys (Fig. 5A and $B$ ). In the enalapril-treated group, hypoxic signals were easily detected in the dilated tubular epithelial cells; however, their overall intensities were similar to the control group (Fig. $5 C$ and $D$ ). In the spironolactone-treated group, the hypoxic signals were more significant than in the control group, and almost all tubular segments in the medulla and
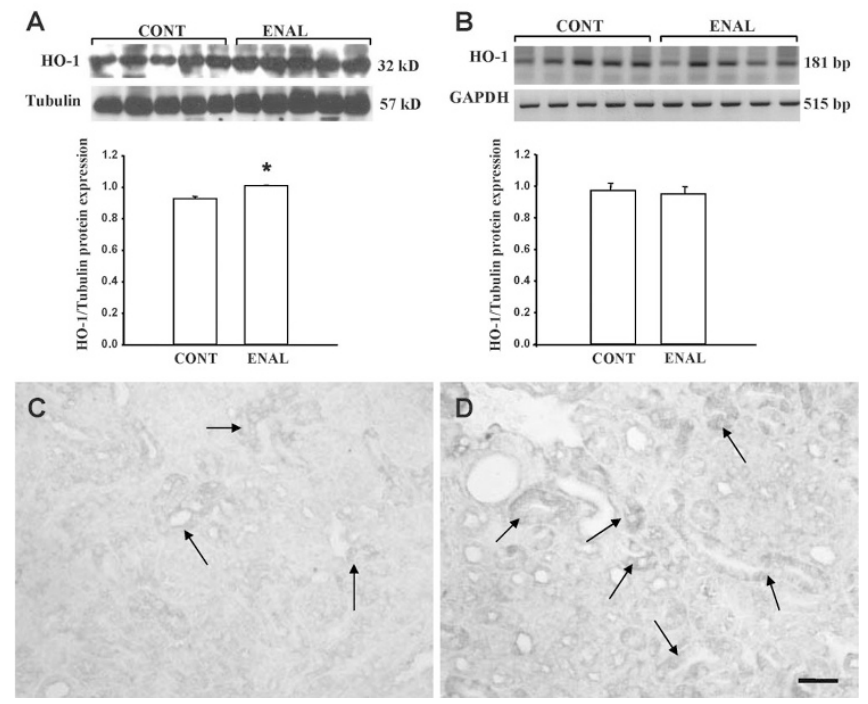

Figure 3. HO-1 expression in the enalapril-treated group. (A) HO-1/tubulin protein expression increased in the enalapril-treated group (ENAL) compared with the control group (CONT); $* p<0.05$. (B) HO-1/GAPDH mRNA expression was not changed. $(C) \mathrm{HO}-1$ expression was observed in some developing and maturing tubules in the newborn control kidney (arrows). (D) In the enalapril-treated kidneys, HO-1 was significantly visible particularly in the dilated cortical tubular epithelial cells (arrows). $C, D$ : bar $25 \mu \mathrm{m}$, original magnification $\times 400$.
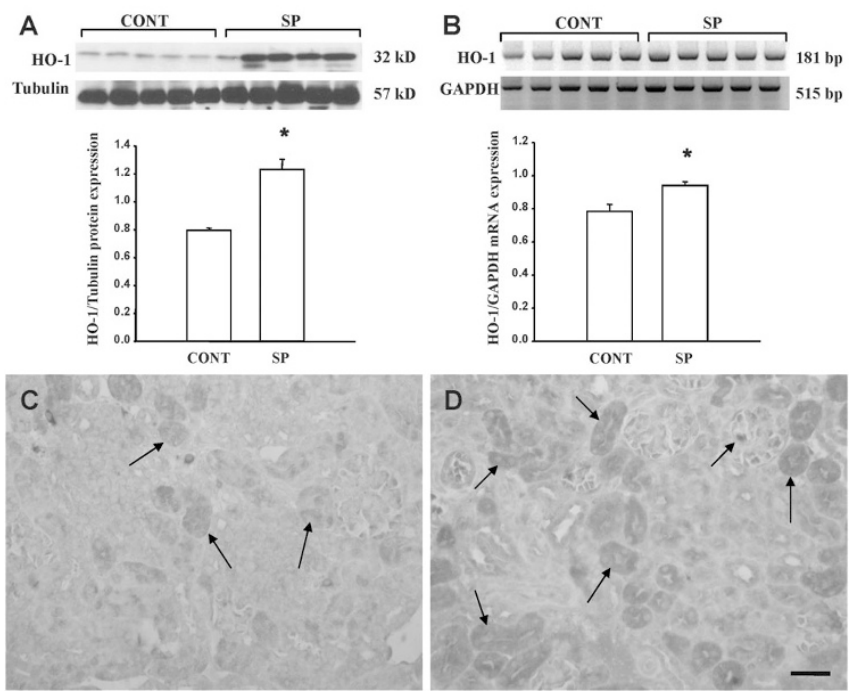

Figure 4. HO-1 expression in the spironolactone-treated group. (A) HO-1/ tubulin protein expression increased in the spironolactone-treated group (SP) compared with the control group (CONT); $* p<0.05$. (B) HO-1/GAPDH mRNA expression increased in the spironolactone-treated group; ${ }^{*} p<0.05$ ). (C) In controls, HO-1 was detected in some tubular epithelial cells (arrows). (D) In the spironolactone-treated kidneys, HO-1 was more robustly stained throughout almost all cortical tubular cells and glomeruli (arrows). C, D bar $25 \mu \mathrm{m}$, original magnification $\times 400$.

cortex showed strong positive pimonidazole staining (Fig. $5 E$ and $F$ ).

\section{DISCUSSION}

The results of this study demonstrate that Aldo blockade or Ang II inhibition, in the developing newborn rat kidney, up-regulated the protein expression of VEGF and HO-1. Although HO-1 mRNA expression was increased in the spi- 


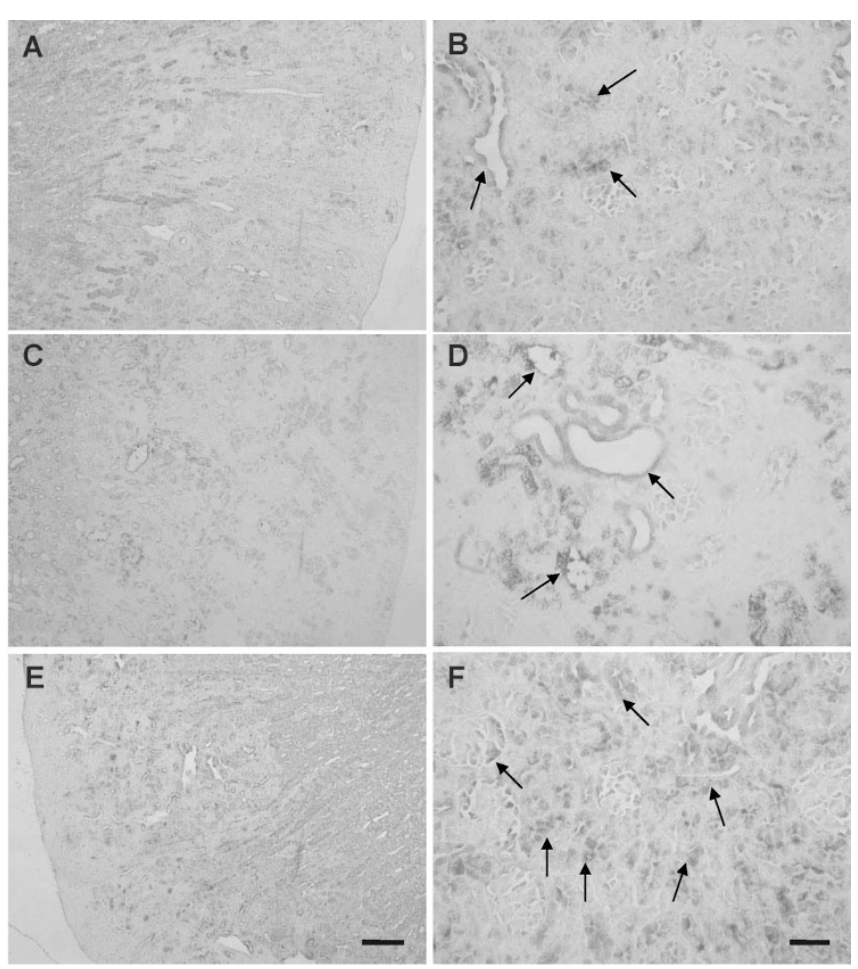

Figure 5. Hypoxyprobe-1 binding in control $(A$ and $B)$, enalapril-treated $(C$ and $D$ ), and spironolactone-treated kidneys $(E$ and $F)$. $A, C, E$ bar $100 \mu \mathrm{m}$, original magnification $\times 100 ; B, D, F$ bar $25 \mu \mathrm{m}, \times 400$.

ronolactone-treated group, the lack of a change in mRNA suggests that the induction mechanism may be mostly posttranscriptional. Induction of hypoxia was increased in the developing rat kidney with spironolactone treatment; however, enalapril did not significantly affect hypoxic signals expressed by pimonidazole staining, which confirmed earlier observations (16).

Accumulating data show that the control of vascular development is complicated and involves cell-cell and cellmatrix interactions and growth factor-receptor signaling. Developmental vascularization must occur with tissue expansion. Hypoxia-responsive systems, including HIF, seem to be key regulators of vasculogenesis and angiogenesis (22). The finding that Aldo inhibition leads to up-regulation of HIF-1 and Ets-1, in association with increased pimonidazole immunoreactivity in the newborn rat kidney (16), suggests that the activity of VEGF and HO-1, the genes induced by HIF, are likely enhanced by spironolactone treatment. Indeed, the findings of this study demonstrate that VEGF and HO-1 protein expression were up-regulated by spironolactone.

Many stimuli, including hypoxia, growth factors, hormones, and oxidative stressors, can increase VEGF expression in vitro. In these cases, increased VEGF expression can be caused in part by increased VEGF gene transcription mediated by the transcription factor HIF-1. HIF-1 binds to a hypoxiaresponsive element located within the VEGF promoter (23). HO-1 expression in renal medullary cells is also transcriptionally regulated via an HIF-1 pathway under normal and hypoxic conditions (22). Moreover, both pharmacologically and genetically induced augmentation of HO-1 expression occurs with an increase of VEGF synthesis under certain experimental conditions $(11,24)$. The findings of this study showed that the simultaneous increase of VEGF and HO-1 activated by spironolactone in newborn rat kidneys was accompanied by enhanced hypoxic signals. Aldo blockade was shown to induce HIF- $1 \alpha$ and its target genes, VEGF and HO-1, mediated by the classic mineralocorticoid receptors in the developing rat kidney. The functional consequences of HIF- $1 \alpha$ upregulation by Aldo blockade in the developing kidney might be explained at least, in part, by the enhanced expression of VEGF and HO-1.

Aldo is a mineralocorticoid hormone produced by the adrenal cortex. In addition to its traditional role of promoting sodium retention, Aldo causes oxidative stress, like Ang II, and stimulates inflammation and fibrosis by activating different transcription factors (25). Recently, Ndisang et al. (26) showed novel links between the HO system, Aldo, and nuclear factor kappa beta in rats. Lai et al. (10) demonstrated that Aldo up-regulated the expression of VEGF in cortical collecting duct epithelial cells through mineralocorticoid receptors, providing experimental evidence for the nonhemodynamic action of Aldo.

Contrary to the observed modulating effects of Aldo and mineralocorticoid receptors on the cardiovascular system and the kidneys in the adult experimental models, little is known about their regulating roles in the neonatal kidney independent of hemodynamic effects. Previous studies have reported on the direct contribution of Aldo on cellular effects in the newborn rat kidney $(16,27)$; however, the exact mechanism of Aldo's nonhemodynamic activity in the developing kidney remains largely unknown.

In this study, VEGF and HO-1 expression was unexpectedly up-regulated in enalapril-treated rats. Considering that HIF- $1 \alpha$ expression and pimonidazole immunoactivity were not changed in a previous study (16), the process might be explained by a HIF-1 independent mechanism. Because the pharmacological effects of angiotensin-converting enzyme (ACE) inhibitors are in part mediated by both reduction of Ang II and accumulation of bradykinin (28), the contribution of the bradykinin pathway to VEGF and HO-1 up-regulation should be considered. Ebrahimian et al. (29) reported that ACE inhibition increases the VEGF protein level by activation of the bradykinin pathway in the ischemic leg of diabetic mice. Li et al. (30) suggested that ACE inhibitors enhance VEGF expression and NO formation that promotes angiogenesis in the setting of tissue ischemia by stimulation of bradykinin receptors. Considering that $\mathrm{HO}-1$ is induced by a range of stimuli including oxidative stress and NO (13), it is possible that NO formation by the bradykinin pathway contributed to the up-regulation of HO-1 in this study. Meanwhile, recent in vivo studies have shown that VEGF regulates HO-1 expression and activity. It has been proposed that HO-1 may amplify its effects through a positive-feedback loop where HO-1 in turn enhances VEGF synthesis $(11,31)$.

A growing body of evidence has supported that Aldo and Ang II are potent mitogenic signal regulating genes involved in antiapoptosis, cell proliferation, and growth (3235). Spironolactone or enalapril presumably interferes with 
renal cell growth, which is accompanied by microvasculature dysfunction in the developing kidney, and creates a harmful environment regardless of hypoxic condition. The triggered deleterious environment, in turn, impacts on hypoxia-related regulatory mechanisms or nonhypoxic HIF target gene expression under relatively normal oxygen pressures. Although Aldo is, to be sure, a downstream effector of Ang II, the significant discrepancy between enalapril and spironolactone treatment in the previous (16) and current studies show that Aldo has direct cellular effects independent of Ang II on the developing kidney. These findings also suggest that hypoxia signal transduction is not a straightforward pathway especially with regard to RAAS-regulated kidney development.

The blockade of the RAAS decreases systemic arterial pressure. Therefore, the renal abnormalities induced by neonatal RAAS blockade might be secondary to an ischemic event caused by decreased renal blood flow and oxygen supply (36). There is evidence that shows that renal abnormalities induced by neonatal RAAS blockade are not necessarily caused by decreased renal oxygen tension but rather mediated by other mechanisms. Administration of nifedipine during the neonatal stage as an arterial pressure lowering drug was not associated with any renal lesions; although nifedipine caused more pronounced arterial pressure reduction than enalapril in weanling rats (37). Nifedipine treatment in the neonatal pig also decreased the mean arterial pressure, local renal blood flow, and medullary oxygen tension, whereas enalapril reduced only the arterial pressure (38). In addition, previous findings support that the renal abnormalities induced by neonatal RAAS blockade are not solely due to hemodynamic effects, because each component of RAAS plays a different role in hypoxiarelated renal growth and development (16).

Renal development in rodents continues into the second postnatal week. Although our experiments involving harvested kidneys at $8 \mathrm{~d}$ postpartum might reflect some roles for VEGF and HO-1 in the development process, it could not be viewed as the direct link with renal microvasculature and glomerular maturation. Whether VEGF and HO-1 could regulate renal microvessel development connected with hypoxia and/or RAAS requires further investigations.

In summary, the results of this study provide further evidence that hypoxia and RAAS could be important factors in kidney development. Aldo blockade might be a potent inducer of hypoxia in developing rat kidneys, and such tissue hypoxia is relevant to the increased expression of VEGF and HO-1 in neonatal rat kidneys. Moreover, Ang II inhibition induces the expression of VEGF and HO-1 in the developing kidney, an effect from the independent action of oxygen deprivation. RAAS might play an important regulatory role in hypoxic and nonhypoxic renal tissue development and growth.

\section{REFERENCES}

1. Hilgers KF, Norwood VF, Gomez RA 1997 Angiotensin's role in renal development. Semin Nephrol 17:492-501
2. Tufro-McReddie A, Romano LM, Harris JM, Ferder L, Gomez RA 1995 Angiotensin II regulates nephrogenesis and renal vascular development. Am J Physiol 269:F110-F115

3. Bernhardt WM, Schmitt R, Rosenberger C, Münchenhagen PM, Gröne HJ, Frei U, Warnecke C, Bachmann S, Wiesener MS, Willam C, Eckardt KU 2006 Expression of hypoxia-inducible transcription factors in developing human and rat kidneys. Kidney Int 69:114-122

4. Freeburg PB, Robert B, St John PL, Abrahamson DR 2003 Podocyte expression of hypoxia inducible factor (HIF)-1 and HIF-2 during glomerular development. J Am Soc Nephrol 14:927-938

5. Wakelin SJ, Marson L, Howie SE, Garden J, Lamb JR, Forsythe JL 2004 The role of vascular endothelial growth factor in the kidney in health and disease. Nephron Physiol 98:73-79

6. Carmeliet P, Ferreira V, Breier G, Pollefeyt S, Kieckens L, Gertsenstein M, Fahrig M, Vandenhoeck A, Harpal K, Eberhardt C, Declercq C, Pawling J, Moons L, Collen D, Risau W, Nagy A 1996 Abnormal blood vessel development and lethality in embryos lacking a single VEGF allele. Nature 380:435-439

7. Larcher F, Murillas R, Bolontrade M, Conti CJ, Jorcano JL 1998 VEGF/VPF overexpression in skin of transgenic mice induces angiogenesis, vascular hyperpermeability and accelerated tumor development. Oncogene 17:303-311

8. Kang YS, Park YG, Kim BK, Han SY, Jee YH, Han KH, Lee MH, Song HK, Cha DR, Kang SW, Han DS 2006 Angiotensin II stimulates the synthesis of vascular endothelial growth factor through the $\mathrm{p} 38$ mitogen activated protein kinase pathway in cultured mouse podocytes. J Mol Endocrinol 36:377-388

9. Feliers D, Gorin Y, Ghosh-Choudhury G, Abboud HE, Kasinath BS 2006 Angiotensin II stimulation of VEGF mRNA translation requires production of reactive oxygen species. Am J Physiol Renal Physiol 290:F927-F936

10. Lai L, Pen A, Hu Y, Ma J, Chen J, Hao CM, Gu Y, Lin S 2007 Aldosterone upregulates vascular endothelial growth factor expression in mouse cortical collecting duct epithelial cells through classic mineralocorticoid receptor. Life Sci 81:570576

11. Dulak J, Loboda A, Zagorska A, Jozkowicz A 2004 Complex role of heme oxygenase-1 in angiogenesis. Antioxid Redox Signal 6:858-866

12. Ryter SW, Otterbein LE, Morse D, Choi AM 2002 Heme oxygenase/carbon monoxide signaling pathways: regulation and functional significance. Mol Cell Biochem 234- 235:249-263

13. Maines MD 1997 The heme oxygenase system: a regulator of second messenger gases. Annu Rev Pharmacol Toxicol 37:517-554

14. Botros FT, Schwartzman ML, Stier CT Jr, Goodman AI, Abraham NG 2005 Increase in heme oxygenase-1 levels ameliorates renovascular hypertension. Kidney Int 68:2745-2755

15. Kruger AL, Peterson S, Turkseven S, Kaminski PM, Zhang FF, Quan S, Wolin MS, Abraham NG 2005 D-4F induces heme oxygenase-1 and extracellular superoxide dismutase, decreases endothelial cell sloughing and improves vascular reactivity in a rat model of diabetes. Circulation 111:3126-3134

16. Yim HE, Kim JH, Yoo KH, Bae IS, Jang GY, Hong YS, Lee JW 2010 Spironolactone, but not enalapril, potentiates hypoxia-inducible factor-1alpha and Ets-1 expression in newborn rat kidney. J Physiol Pharmacol 61:73-81

17. Richard DE, Berra E, Pouyssegur J 2000 Nonhypoxic pathway mediates the induction of hypoxia-inducible factor 1alpha in vascular smooth muscle cells. J Biol Chem 275:26765-26771

18. Schofield CJ, Ratcliffe PJ 2004 Oxygen sensing by HIF hydroxylases. Nat Rev Mol Cell Biol 5:343-354

19. Tso JY, Sun XH, Kao TH, Reece KS, Wu R 1985 Isolation and characterization of rat and human glyceraldehyde-3-phosphate dehydrogenase cDNAs: genomic complexity and molecular evolution of the gene. Nucleic Acids Res 13:24852502

20. Bortolini MA, Silva ID, Hamerski MG, Castro RA, Sartori MG, Girao MJ 2007 Influence of ovarian hormones deprivation on gene expression in the lower urinary tract of rats. Int Braz J Urol 33:544-552

21. Wang HH, Zhou HY, Chen CC, Zhang XL, Cheng G 2007 Propofol attenuation of renal ischemia/reperfusion injury involves heme oxygenase-1. Acta Pharmacol Sin 28:1175-1180

22. Yang ZZ, Zou AP 2001 Transcriptional regulation of heme oxygenases by HIF1alpha in renal medullary interstitial cells. Am J Physiol Renal Physiol 281:F900F908

23. Forsythe JA, Jiang BH, Iyer NV, Agani F, Leung SW, Koos RD, Semenza GL 1996 Activation of vascular endothelial growth factor gene transcription by hypoxiainducible factor 1. Mol Cell Biol 16:4604-4613

24. Fernandez M, Bonkovsky HL 2003 Vascular endothelial growth factor increases heme oxygenase-1 protein expression in the chick embryo chorioallantoic membrane. Br J Pharmacol 139:634-640

25. Iglarz M, Touyz RM, Viel EC, Amiri F, Schiffrin EL 2004 Involvement of oxidative stress in the profibrotic action of aldosterone. Interaction with the renin-angiotension system. Am J Hypertens 17:597-603

26. Ndisang JF, Lane N, Jadhav A 2008 Crosstalk between the heme oxygenase system, aldosterone, and phospholipase C in hypertension. J Hypertens 26:1188-1199

27. Yim HE, Yoo KH, Bae IS, Jang GY, Hong YS, Lee JW 2009 Aldosterone regulates cellular turnover and mitogen-activated protein kinase family expression in the neonatal rat kidney. J Cell Physiol 219:724-733

28. Gainer JV, Morrow JD, Loveland A, King DJ, Brown NJ 1998 Effect of bradykininreceptor blockade on the response to angiotensin-converting-enzyme inhibitor in normotensive and hypertensive subjects. N Engl J Med 339:1285-1292

29. Ebrahimian TG, Tamarat R, Clergue M, Duriez M, Levy BI, Silvestre JS 2005 Dual effect of angiotensin-converting enzyme inhibition on angiogenesis in type 1 diabetic mice. Arterioscler Thromb Vasc Biol 25:65-70 
30. Li P, Kondo T, Numaguchi Y, Kobayashi K, Aoki M, Inoue N, Okumura K, Murohara T 2008 Role of bradykinin, nitric oxide, and angiotensin II type 2 receptor in imidapril-induced angiogenesis. Hypertension 51:252-258

31. Dulak J, Józkowicz A, Foresti R, Kasza A, Frick M, Huk I, Green CJ, Pachinger O, Weidinger F, Motterlini R 2002 Heme oxygenase activity modulates vascular endothelial growth factor synthesis in vascular smooth muscle cells. Antioxid Redox Signal 4:229-240

32. Choi BM, Yoo KH, Bae IS, Oh MH, Hong YS, Lee JW, Kim SK 2005 Angiotensinconverting enzyme inhibition modulates mitogen-activated protein kinase family expressions in the neonatal rat kidney. Pediatr Res 57:115-123

33. Ishizawa K, Izawa Y, Ito H, Miki C, Miyata K, Fujita Y, Kanematsu Y, Tsuchiya K, Tamaki T, Nishiyama A, Yoshizumi M 2005 Aldosterone stimulates vascular smooth muscle cell proliferation via big mitogen-activated protein kinase 1 activation. Hypertension 46:1046-1052
34. Nagai Y, Miyata K, Sun GP, Rahman M, Kimura S, Miyatake A, Kiyomoto H, Kohno M, Abe Y, Yoshizumi M, Nishiyama A 2005 Aldosterone stimulates collagen gene expression and synthesis via activation of ERK1/2 in rat renal fibroblasts. Hypertension 46:1039-1045

35. Rüster C, Wolf G 2006 Renin-angiotensin-aldosterone system and progression of renal disease. J Am Soc Nephrol 17:2985-2991

36. Chen Y, Lasaitiene D, Friberg P 2004 The renin-angiotensin system in kidney development. Acta Physiol Scand 181:529-535

37. Guron G, Nilsson A, Nitescu N, Nielsen S, Sundelin B, Frøkiaer J, Friberg P 1999 Mechanisms of impaired urinary concentrating ability in adult rats treated neonatally with enalapril. Acta Physiol Scand 165:103-112

38. Nilsson AB, Friberg P 2000 Acute renal responses to angiotensin-converting enzyme inhibition in the neonatal pig. Pediatr Nephrol 14:1071-1076 